\title{
Ellas hacen, otros dicen, ellas son. Roles femeninos en la publicidad de la radio española
}

\section{They make, others say, they are: female roles on Spanish radio advertising}

\author{
Teresa Piñeiro-Otero. Universidade da Coruña
}

Recibido: 20-XII-2010 - Aceptado: 29-XII-2011

Resumen:

El relevante papel asumido por la publicidad como agente socializador ha suscitado la preocupación por el uso que esta realiza de determinadas representaciones femeninas. Esta preocupación se ha centrado en la publicidad televisiva y gráfica, dejando relegado al medio sonoro. El objeto del presente trabajo ha consistido en conocer aquellas representaciones femeninas más frecuentes en la publicidad radiofónica, para lo que se ha utilizado el análisis de contenido como metodología de investigación. Un análisis que ha permitido concluir la utilización, en la publicidad sonora, de roles tradicionales como el de madre, ama de casa o trabajadores en puestos auxiliares.

Palabras clave:

Publicidad, radio, mujeres, representaciones femeninas, roles de género

Abstract:

Relevant role assumed by advertising as socializer agent has worried about advertising feminine representation use. Worries focused on television and press advertising, but forgotten on radio advertising. The present work aims to know those more frequent feminine depictions in radio advertising, using content analysis as research methodology This analysis has allowed us to conclude the utilization, in the sonorous advertising, of traditional roles as mother, housewife or worker in auxiliary positions.

Keywords:

Advertising, radio, women, feminine representations, gender roles 


\section{Introducción}

A partir de la segunda mitad del siglo XX diversos factores de carácter social y económico -entre los que destaca la incorporación "masiva" de las mujeres al mercado laboral y su consecuente repercusión en las estructuras familiarespropiciaron modificaciones en los papeles desempleados por ambos géneros en las sociedades occidentales.

Dicha situación supuso un cambio en el modo de socialización y de individualización de las mujeres, que dio paso a un nuevo modelo histórico: la "tercera mujer" (Lipovetsky, 2002). Una modificación en el modelo cultural que se traduce en la igualación de la condiciones hombre-mujer, la consideración del trabajo de las mujeres como medio de independencia personal y la paulatina asunción -por parte de los varones- de tareas consideradas hasta el momento como "femeninas".

Estos nuevos roles sociales se han reflejado en múltiples aspectos de la vida cotidiana y, como extensión, en uno de sus máximos exponentes: la publicidad. Sin embargo, son numerosas las críticas hacia la poca sensibilidad de los creativos a la hora de reflejar este cambio social en los mensajes publicitarios (Galán y Sánchez, 2005: 792); inclusive en un momento en que las representaciones sexistas parecen haberse moderado (Bigné y Cruz, 2000: 166).

La publicidad se configura como uno de los principales agentes socializadores, lo que la sitúa como un marco de referencia fundamental para el análisis de las representaciones sociales de género. Sus mensajes suponen exponentes básicos de aquellas concepciones socialmente establecidas sobre la identidad femenina y masculina, convirtiendo a sus protagonistas patrones ideales de conducta.

En este sentido, la publicidad constituye un indicador de las condiciones de igualdad -o desigualdad- entre mujeres y hombres en una sociedad determinada (Bernard y López Lita, 2007: 214). El mundo que recrean los anuncios refleja un reparto de papeles en función del género similar a la realidad, al tiempo que transmite a su audiencia una propuesta determinada, un modelo a imitar (De Pablos y otros, 2005).

No obstante, el estudio de las diferentes representaciones de género vehiculadas por los mensajes publicitarios no ha dado lugar a un volumen de análisis equiparable. El abuso que los mensajes publicitarios realizan de las imágenes femeninas, junto con el alto grado de estereotipia que presentan, ha favorecido que la mayor parte de las investigaciones sobre género y publicidad fijasen en ellas su centro de interés: “(...) Las imágenes que se difunden de la mujer a través de los medios, suelen ser negativas, estereotipadas, inexactas y violentas, describiéndose las mujeres más por su apariencia que por sus capacidades" (López Lita y Bernad, 2007: 216).

Estos trabajos en torno a las representaciones femeninas en la publicidad se han basado el hecho de que a las mujeres les queda por definir su imagen respecto a la del varón, desde donde siempre han sido contempladas (Areste, 2003: 104). 


\section{Las representaciones femeninas en la publicidad. Una aproximación}

A pesar de que la publicidad actual se encuentra -siguiendo a Elósegui (1998)- en la "tercera etapa”, que reivindica la corresponsabilidad o roles compartidos tanto en el ámbito laboral como en el doméstico, los estudios efectuados sobre las representaciones de género en la publicidad continúan subrayando un enfoque sexista. Por otra parte, dichos estudios no tendrían sentido de no haberse producido una evolución sociocultural reflejada, en mayor o menor medida, en los anuncios publicitarios (Royo y otros, 2005: 116).

En lo que se refiere al contexto español, Sánchez Aranda, García Ortega, Grandío y Berganza (2002) subrayaron una evolución positiva de las representaciones femeninas en la publicidad. Esta evolución va a colisionar, siguiendo a Berganza y Del Hoyo, “(...) con la fortaleza del estereotipo que guía el proceso de comunicación y dentro del cual la propuesta innovadora no es sino una estrategia más para obtener los mismos tópicos valores” (Berganza y del Hoyo 2006: 173).

Dentro del ámbito de los valores y contenidos publicitarios, las representaciones femeninas han sido las que han acaparado mayor atención desde el punto de vista de los usuarios, asociaciones, poderes públicos y comunidad científica; este interés se puede ver reflejado en el importante volumen de estudios relativos a publicidad y representaciones de género/femeninas.

Como parte del corpus teórico de los Gender Studies, en las últimas décadas se han llevado a cabo numerosas investigaciones en torno a las representaciones publicitarias femeninas; en su mayoría desde la perspectiva del análisis de contenido. Entre estas investigaciones se pueden reseñar, en el ámbito internacional, las desarrolladas por Courtney y Lockeretz (1971) o Goffman (1976) sobre las revistas, las de Courtney y Whipple (1974), McArthur y Resko (1975), Manstead y McCulloch (1981), Durkin (1985) ${ }^{1}$, Harris y Stobart (1986), Rak y McCullen (1987), Furnham y Voli (1989), Ferrante, Hayes, y Kingsley (1988), Gilly (1988), Lovdal (1989), Craig (1992), Furnham y Bitar (1993), Kolbe y Langefeld (1993), Neto y Pinto (1998) o Furnham y Mak (1999) sobre la televisión; y Furnham y Schofield (1986), Hurtz y Durkin (1997), Furnham y Thomson (1999) o Neto y Santos (2004) sobre la publicidad radiofónica.

En el marco español los estudios relativos a las representaciones de género/femeninas en la publicidad son más tardíos, aunque han vivido una importante eclosión en los últimos años. Algunas de estas investigaciones son las de Méndiz (1988); Freixas, Guerra y Peinado (2001) o González Solaz y García Cubells (2001) sobre la televisión, y Peña-Marín y Fabretti (1990); Bermejo, Carballido, Patricio y Ramos (1994); Martín Serrano, Martín Serrano y Baca (1995); Del Moral (2000); Bernárdez (2000); Correa, Guzmán, y Aguaded (2000); Sánchez Aranda, García Ortega, Grandío y Berganza (2002); Sánchez Aranda (2003) o Areste (2003) sobre la publicidad en general.

1 Además del estudio sobre contenido, Durkin publicó otros dos artículos que, bajo el mismo título, "Television and sex-role acquisition" centran su atención en los efectos (II) y en los contra estereotipos (III). 
Una aproximación a dichos trabajos podría llevar a concluir que la televisión, objeto de estudio de la mayor parte de investigaciones consultadas, es el medio de comunicación cuyos mensajes muestran unas representaciones femeninas más sexistas. Esta aseveración parece corroborarse si se atiende a las denuncias efectuadas ante el Observatorio de la Imagen de las Mujeres (en adelante Observatorio), cuyo objeto es la publicidad televisiva en un $42 \%$ de los casos (Instituto de la Mujer, 1999-2008).

Asimismo, resulta patente la escasa presencia de estudios sobre el medio radiofónico, aún cuando diversos trabajos han puesto de relevancia la existencia de representaciones femeninas de carácter sexista en la publicidad sonora (Furham y Schofield, 1986; Hurtz y Durkin, 1997; Furham y Thomson, 1999; Neto y Santos, 2004).

La radio es la gran ausente en la investigación sobre las representaciones publicitarias de género pese a ser un medio publicitario "clásico" y de gran audiencia.

Tabla I. Estudios internacionales sobre representaciones de género en la publicidad radiofónica

\begin{tabular}{|l|l|l|}
\hline \multicolumn{3}{|c|}{ Estudios internacionales } \\
\hline 1986 & Furnham y Schofield & Análisis de contenido \\
\hline 1997 & Hurtz y Durkin & Efectos \\
\hline 1999 & Furnham y Thomson & Análisis de contenido \\
\hline 2004 & Neto y Santos & Análisis de contenido \\
\hline 2007 & Monk-Turner, Kouts, Parris y Webb & Análisis de contenido \\
\hline
\end{tabular}

Fuente: Elaboración propia.

Esta infrarrepresentación del medio sonoro se repite, con apenas cambios, en el contexto nacional. En este ámbito reseñable el repunte -en los últimos años-de trabajos relativos a las representaciones femeninas en la publicidad radiofónica, tras más de una década sin producción científica sobre la materia. 
Tabla II. Estudios en el ámbito nacional sobre representaciones de género en la publicidad radiofónica

\begin{tabular}{|l|l|l|}
\hline \multicolumn{2}{|c|}{ Estudios en España } \\
\hline 1985 & Lowy, Crespo y Roda & Radio \\
\hline 2007 & Gil & Análisis de contenido \\
\hline 2009 & Fajula, Fernández Souto y Barbeito & Análisis de contenido \\
\hline 2009 & Piñeiro-Otero & Análisis de contenido \\
\hline
\end{tabular}

Fuente: Elaboración propia.

Estas investigaciones han constatado la utilización, en la publicidad radiofónica española, de representaciones de género de carácter sexista.

La percepción de un tratamiento más respetuoso de las representaciones femeninas, reflejada en el escaso porcentaje de denuncias ante el Observatorio (2,5\% en todo el período 1999-2008), podría relacionarse con la particular construcción de los personajes radiofónicos. En este proceso de caracterización los atributos visuales -que adornan a los personajes publicitarios televisivos- son sustituidos por atributos verbales, perfectamente articulados con otro tipo de recursos sonoros.

La hipótesis de partida del presente trabajo se fundamentó en el hecho de que la publicidad, para lograr la máxima comprensión de sus mensajes, se vale de la utilización de aquellas imágenes femeninas que resulten más familiares para su público. Esta familiaridad se consigue a costa de la revisión de dichas representaciones y, por ende, de la utilización de aquellos roles de género más manidos.

En este sentido, el objeto del presente estudio fue el de conocer los papeles que la publicidad sonora asigna a los personajes femeninos y, por extensión, a los masculinos, con la intención de determinar la existencia de diferencias en la distribución de los roles según el género. Asimismo se pretendió analizar la existencia de sexismo en dichas representaciones; esto es, determinar si la publicidad radiofónica subvalora, excluye, subrepresenta o estereotipa a los personajes en función de su pertenencia a uno u otro género (Michel, 1987: 17).

\section{Metodología}

Para abordar el objeto de estudio, los diferentes papeles que la publicidad radiofónica asigna a los personajes femeninos y a sus correspondientes masculinos, se optó por llevar a cabo un análisis de contenido de aquellas cuñas presentadas al Festival Publicitario de San Sebastián entre 1996 y 2002 (ambos inclusive). Es decir, en el período comprendido entre la in- 
corporación al certamen del galardón de radio y su apertura al mundo latino. Dicha selección acotó el estudio a un tipo de publicidad, de mayor calidad, y a un momento concreto del festival dedicado exclusivamente a la producción española.

Ante el importante volumen de esta muestra de partida, y dado el especial interés hacia las representaciones femeninas, se optó por limitar el estudio a aquellos anuncios radiofónicos en los que apareciese-al menos- una voz de mujer. De este modo, de las 915 cuñas inscritas al festival durante este período, solamente 379 anuncios conformaron la muestra final.

Esta nueva selección permitió analizar los papeles que la publicidad sonora determina para las mujeres y para aquellos varones con los que interactúan dentro de la ficción publicitaria.

\subsection{Unidad de análisis}

Una vez establecida la muestra de estudio fue preciso concretar aquellos personajes de cada anuncio considerados unidades de análisis, en busca de estandarizar un número de sujetos por mensaje. Para ello se tomó como referencia "The portrayal of men and women in American televisión commercials” de McArthur y Resko (1975)², que llevó a determinar como unidades de análisis los dos personajes principales de cada anuncio, inclusive en aquellos casos en que la voz femenina no se correspondiese con la de ninguno de los protagonistas.

En aquellos mensajes publicitarios en los que la selección de los dos protagonistas generase algún tipo de controversia, se primó la selección de las voces femeninas con la intención de estimular su representatividad. Asimismo, en el caso de existir un grupo más o menos compacto de personajes en el anuncio, se optó por su análisis conjunto como protagonistas corales, tomando su caracterización como individual (como un solo personaje con un rol y unas cualidades concretas).

Atendiendo a estas particularidades, se estableció una selección de 652 sujetos, de los cuáles 280 se correspondieron con personajes masculinos, 341 femeninos, y 31 corales (15 masculinos y 16 femeninos).

Además de la selección de los dos protagonistas principales del relato publicitario, resultó de especial interés para este estudio su orden dentro del mismo. Un orden que estuvo marcado por las intervenciones de los protagonistas dentro de la interacción publicitaria, y que fue tenido en cuenta para su análisis (Personaje 1 y Personaje 2).

\subsection{Herramienta de análisis}

Determinados los personajes unidad de análisis, se elaboró una ficha para estudiar los diferentes roles desempeñados por estos protagonistas, femeninos y masculinos, dentro del relato publicitario. Esta herramienta de trabajo se construyó ba-

2 Este artículo de McArthur y Resko, además de constituir una referencia obligada en los estudios sobre representaciones publicitarias de género, supone una influencia importante en el diseño metodológico de los mismos. En este sentido, gran parte de los trabajos consultados han establecido como unidad de análisis los dos personajes principales de cada anuncio. 
sándose en una serie de estudios de referencia en el ámbito de la investigación sobre género y publicidad, entre los que destaca el de McArthur y Resko (1975).

Además del género, número y orden de los personajes principales en la interacción publicitaria se han establecido las siguientes variables de análisis: rol desarrollado por los protagonistas, factor determinante en la construcción sonora de dicho rol, relación entre ambos roles y localización.

La categoría "Rol desarrollado por los personajes", variable esencial de este trabajo en cuanto se refiere a los papeles asumidos por los protagonistas dentro del relato publicitario, fue adoptada del estudio de McArthur y Resko. En su adecuación al ámbito concreto de la publicidad radiofónica se establecieron un total de 16 codificadores.

A la tipología clásica de esposo/a, padre/madre, ama de casa, trabajador/a (que unifica las distinción propuesta por McArthur y Resko entre obrero/a y profesional) celebridad de la vida real, narradorla, novio/a y otros (por otros roles no mayoritarios), se incorporaron otros descriptores como hijola, vecinola, compañerola, papel (personajes que recrean celebridades de ficción como Escarlata O`Hara o Tarzán), no relevante para conseguir una mayor definición de los resultados obtenidos.

Asimismo se estableció un desdoblamiento del descriptor trabajador/a en periodista y teleoperador/a, debido a la importante presencia de personajes que desarrollan su función dentro de estas actividades laborales.

Directamente relacionada con el rol de los personajes dentro del relato se encuentra la variable "factor determinante en la construcción sonora de dicho rol"; categoría que hace referencia al elemento concluyente en la identificación del papel desarrollado por un protagonista concreto.

Si bien la caracterización de un personaje radiofónico puede ser múltiple: a través de sus acciones, sus atributos verbales, las alusiones de otros personajes y el espacio en el que se inserta (que serán utilizados como codificadores); resulta posible señalar un factor principal en la construcción del rol concreto. Un factor cuya relevancia en la caracterización del personaje se señaló en función de si se trataba del único calificador, si se configuraba como elemento principal en la construcción del protagonista o si su presencia permitía despejar dudas sobre el papel desarrollado.

Otra de las categorías incluidas en la herramienta de trabajo para implementar el análisis de los roles publicitarios es la de "relación establecida entre ambos roles", con la que se abordó la relación entablada por los personajes en la interacción publicitaria. . Los clasificadores que señalan esta relación se concretan en seis: complementarios, en referencia a roles accesorios del tipo de esposo-esposa o madre-hijo; opuestos, para definir la relación entre personajes contrapuestos (bueno-malo); iguales, cuando se trata de personajes del mismo género que desempeñan el mismo papel; paralelos, cuando se trata de papeles iguales asumidos por personajes de distinto género; contrapunto, en aquellos protagonistas cuya función publicitaria es la de contraste armónico entre dos voces y otros. 
Por último, la categoría "localización" -adaptada del estudio "Gender role stereotyping in advertisements on two British radio station” de Furham y Thomson (1999)- remite al espacio donde se sitúan los personajes principales en el transcurso de la interacción publicitaria. Para esta variable se van a establecer cinco clasificadores diferentes: casa, lugar de trabajo, espacio interior (no definido como hogar o trabajo), espacio exterior y no relevante.

\section{Roles desempeñados por los personajes en el relato publicitario}

Con el propósito de conocer el tipo de papeles que la publicidad radiofónica asigna a las representaciones femeninas dentro del mensaje, se han analizado los roles asumidos por los dos personajes principales de la interacción publicitaria. Este análisis consideró también a los protagonistas masculinos de la muestra, con la intención de establecer similitudes y diferencias en la asignación de papeles que la publicidad sonora realiza en función del género.

En este sentido, el estudio de las cuñas seleccionadas permitió señalar aquellas representaciones más frecuentes de la publicidad radiofónica española, así como realizar una aproximación a los papeles que desarrollan los personajes femeninos dentro de sus mensajes.

Para determinar el tipo de rol asumido se han tenido en cuenta cuatro factores principales: las acciones del protagonista, sus atributos, las alusiones de otros personajes presentes el relato publicitario y el paisaje sonoro en el que se insertan.

Figura 1. Factores determinantes del rol desempeñado.

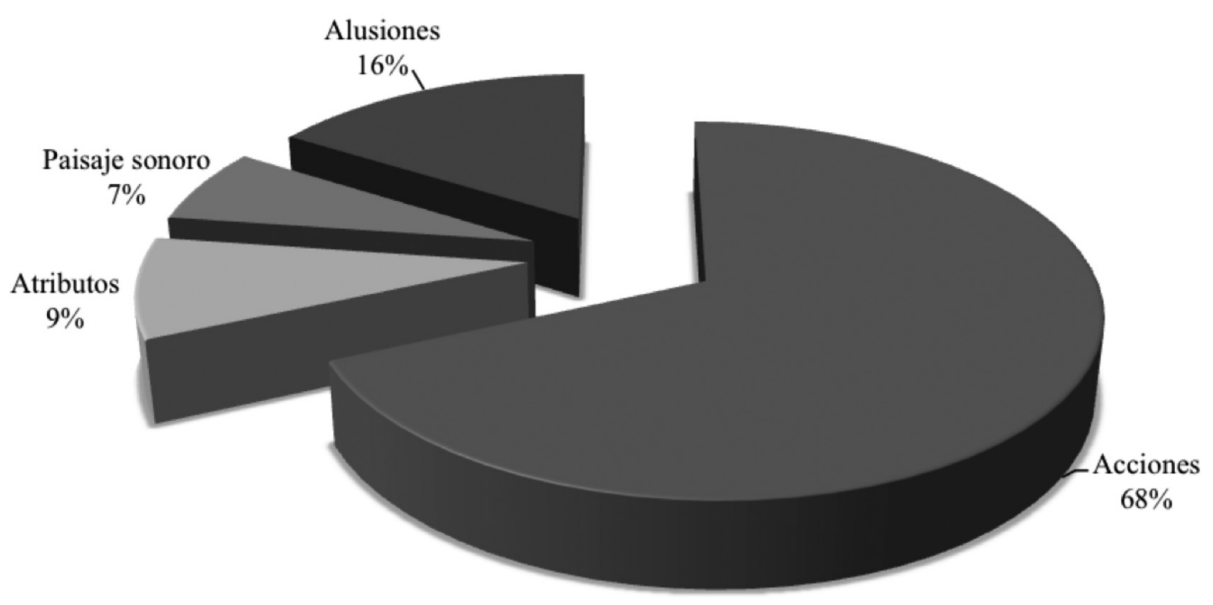

Fuente: Elaboración propia 
Pese a que estos elementos se encuentran presentes, en mayor o menor medida, en la construcción de los personajes sonoros, ha sido posible señalar un factor determinante en el rol desempeñado por los protagonistas en el relato ${ }^{3}$.

El principal caracterizador de los papeles desempeñados por los personajes de la muestra fue el de las acciones. En efecto, más de la mitad de los personajes pudieron asociarse a un rol determinado gracias a la información aportada por sus acciones, vehiculadas por medio de la interacción verbal con otros individuos en la ficción publicitaria.

Además de las acciones de los protagonistas, aunque en menor medida, destacaron las alusiones de otros individuos como caracterizadores del rol desarrollado. Dichas alusiones, que determinaron de modo efectivo el papel asumido por los personajes dentro del relato publicitario, se utilizaron principalmente entre roles del ámbito familiar a modo de vocativo.

Por su parte, los atributos vocales resultaron determinantes en el caso de los definidores celebridad y papel, unos roles cuya construcción se fundamentó en la imitación de los principales rasgos fónicos de personalidades de la vida real y de la ficción.

Finalmente, el paisaje sonoro también contribuyó en la vinculación de los personajes a un determinado papel, especialmente en aquellos casos en los que la información aportada por los restantes clasificadores suscitase dudas.

Todos estos caracterizadores permitieron vincular los diferentes personajes analizados con un rol concreto, hasta completar los 16 descriptores señalados.

Figura 2. Roles más frecuentes en la muestra de estudio.

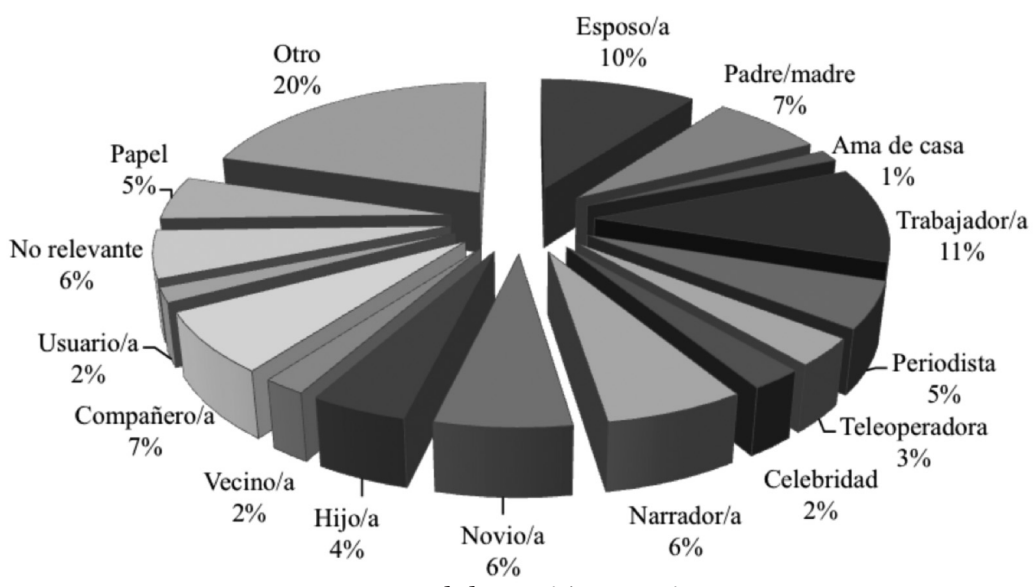

Fuente: Elaboración propia.

3 O la ausencia de un factor determinante en la caracterización de aquellos personajes cuyo rol no resulta significativo para la interacción publicitaria y que han sido catalogados con el descriptor "no relevante". 
Entre los diferentes roles asumidos por los personajes principales en la interacción publicitaria destacan el de trabajadorla (11\%) y el de esposo/a (10\%). Unos papeles publicitarios que se podrían considerar "típicos” y que ya estaban presentes en el estudio de referencia (de McArthur y Resko, 1975).

En el caso concreto del rol de trabajador/a, esta hegemonía se incrementa con la suma de los descriptores de periodista y teleoperadora (con un 5\% y $3 \%$ respectivamente). Unos descriptores vinculados a la actividad laboral de los dos personajes principales dentro del anuncio, que adquirieron entidad propia ante el elevado número de protagonistas que desarrollaron específicamente estos papeles. No en vano, ambas profesiones se adecuan perfectamente al mensaje radiofónico dada su esencia eminentemente sonora.

Otros descriptores que adquieren especial proyección en el caso de la publicidad radiofónica además de los clásicos padre/madre, novio/a o compañero/a, son los de no relevante y papel (con un $6 \%$ y $5 \%$, respectivamente).

La particular construcción de los personajes radiofónicos en función de sus acciones, atributos, alusiones de otros individuos con los que interactúan y el paisaje sonoro en el que se insertan, favorece la aparición de personajes sin papel definido. Este tipo de personajes, no exclusivo de la publicidad sonora, adquiere en la radio su mayor expresión dada la facilidad del medio de prescindir de un espacio concreto en sus mensajes.

Asimismo, esta caracterización de los personajes radiofónicos permite la construcción de protagonistas de ficción a partir de la reproducción de aquellas particularidades sonoras que resulten más familiares entre la audiencia. En efecto, el definidor papel incluye a algunos personajes cuyos rasgos fónicos, el paisaje sonoro en el que se insertan y su discurso, remiten a un protagonista cinematográfico concreto o a una escena famosa de una película. Una circunstancia que también es aprovechada por la publicidad radiofónica para suscitar la imagen de un determinado personaje famoso, a partir de la emulación de los rasgos más característicos de su voz.

\subsection{Principales roles en función del género del personaje}

El análisis de los principales roles desempeñados por los protagonistas de la muestra de estudio reflejó diferencias en la ocupación de los personajes femeninos y masculinos dentro de la interacción publicitaria.

Estas diferencias no sólo permitieron destacar la presencia de una serie de papeles asumidos mayoritariamente por mujeres o por varones (como el de madre o el del hijo, respectivamente), sino que pusieron de relevancia la existencia de roles exclusivamente femeninos (ama de casa y teleoperadora) o masculinos (usuario).

Atendiendo a la proporción de personajes mujeres o varones que asumen cada papel, se pueden clasificar los diferentes roles en cinco apartados: femeninos, masculinos, mayoritariamente femeninos, mayoritariamente masculinos e iguales. 
En este sentido resulta preciso destacar que la particular selección objeto de estudio ha promovido una sobrerrepresentación de los personajes femeninos (357 frente a 295 masculinos) que se refleja en diversos descriptores.

Figura 3. Roles en función del género del personaje.

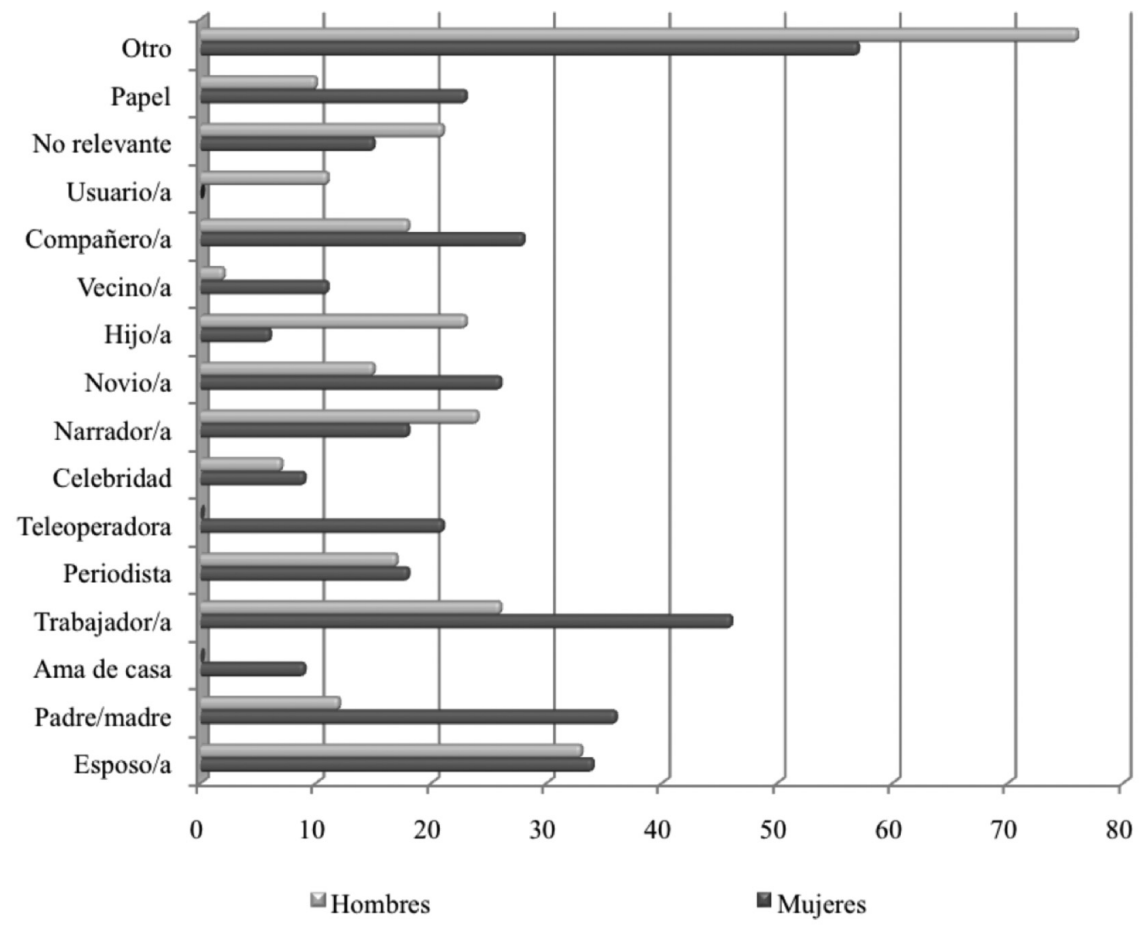

Fuente: Elaboración propia.

El análisis de la muestra ha permitido señalar como roles femeninos los de ama de casa y de teleoperadora. Esta presencia de personajes femeninos en exclusiva dentro de estos papeles se corresponde con una perspectiva muy tradicional de las representaciones publicitarias. En efecto, el rol de ama de casa supone una de las representaciones de mujer más típicas de la publicidad de todos los tiempos.

Su correspondiente masculino, aquel papel desempeñado únicamente por personajes varones dentro de la muestra, es el de usuario. Papel que desarrollan los protagonistas que hacen referencia a las características de un determinado producto/servicio, convirtiéndose en prescriptores espontáneos del mismo. 
Dada la particular selección de anuncios, los roles con mayoría femenina constituyen el apartado más numeroso de la muestra. Un apartado que incluye el rol de padre/madre (36 personajes femeninos frente a 12 masculinos), el de trabajadorla (46 frente a 26 masculinos), el de novio/a (26 frente a 15 masculinos), el de vecino/a (11 frente a 2 masculinos), el de compañero/a (28 frente a 18 masculinos), y papel (23 frente a 10 masculinos).

Esta mayor presencia de las voces femeninas en determinados roles está motivada por la muestra objeto de estudio. En efecto, mientras los personajes femeninos configuran el total de los protagonistas principales de los anuncios radiofónicos del Festival Publicitario de San Sebastián, los masculinos solamente se corresponden con el $41 \%$ de las piezas presentadas. Una circunstancia que va a afectar, especialmente, a roles como el de trabajador, compañero o papel; representaciones masculinas frecuentes de la publicidad que adquieren especial proyección en la comunicación radiofónica.

Por su parte, entre los roles con mayoría masculina, se pueden destacar el de narrador/a (24 personajes masculinos frente a 18 femeninos), el de hijola (23 frente a 6 femeninos) y no relevante ( 21 frente a 15 femeninos). Además de en estos roles, resulta reseñable la mayor presencia de personajes masculinos en el descriptor otros; una mayoría que responde al hecho de que la herramienta de trabajo fuese concebida, fundamentalmente, para el análisis de las representaciones femeninas.

Entre los roles que mantienen cierto equilibrio de personajes masculinos y femeninos, destacan el de esposo/a (34 femeninos y 33 masculinos) y el de periodista (18 femeninos y 17 masculinos). Este equilibrio de personajes en función del género atiende a diversas cuestiones: en el caso de esposo/a, esta proporción se debe a que los personajes masculinos y femeninos que desarrollan dicho papel suelen presentar una relación de complementariedad. Por su parte, el papel de periodista, una de las profesiones más utilizadas por la publicidad sonora dada su posibilidad de aprovechar la ausencia de barreras tajantes entre información y publicidad, presenta una distribución equilibrada debido a la selección objeto de estudio.

\section{2. Roles desempeñados en función del orden de los personajes en la interacción}

Además de subrayar diferencias en los papeles desempeñados por mujeres y hombres dentro de la ficción publicitaria, el estudio de la muestra permitió señalar su desigual distribución atendiendo a su orden en el relato. En efecto, algunos de los roles analizados presentaron variaciones en función de si se toma como referencia al personaje que daba inicio a la interacción (Personaje 1), o a su interlocutor (Personaje 2).

Previamente al estudio de los roles de los personajes en función del género y lugar en la interacción verbal, se hace preciso conocer el orden que ocupan estos protagonistas en el anuncio publicitario y, por tanto, en su codificación. 
Tabla III. Personajes en función del género y orden en el relato.

\begin{tabular}{|l|l|l|}
\hline \multicolumn{2}{|c|}{ Personajes en función del género y orden en el relato. } \\
\hline & Personaje 1 & Personaje 2 \\
\hline Hombre & 165 & 115 \\
\hline Mujer & 191 & 150 \\
\hline Hombres & 10 & 5 \\
\hline Mujeres & 4 & 12 \\
\hline
\end{tabular}

Fuente: Elaboración propia.

En la selección analizada resulta preciso señalar una mayoría de Personajes 1 (370 frente a 282 Personajes 2) debido a la existencia de numerosos mensajes publicitarios que cuentan con un solo protagonista (un total de 88 cuñas). Estos personajes que inician la interacción publicitaria son femeninos en el 53\% de los casos, lo que implica una ligera ventaja de voces de mujeres sobre las de los varones que pierde relevancia de atender a porcentajes relativos.

En efecto, prácticamente el $60 \%$ de los protagonistas varones ocupan el lugar del Personaje 1, lo que suponde una ventaja de más de cinco puntos porcentuales respecto a los personajes femeninos en ese papel (54\%). De este modo, se pudo constar la mayor presencia de personajes varones que toman la iniciativa en la interacción publicitaria, aún teniendo en cuenta que en prácticamente una tercera parte de la muestra (115 cuñas) no existen voces masculinas protagonistas.

Si se presta atención a los diferentes papeles desempeñados por los personajes dentro del relato, el orden que éstos asumen en la interacción publicitaria puede ofrecer información relevante para el análisis de los roles en función del género. 
Tabla IV. Roles en función del género y su orden en el relato.

\begin{tabular}{|c|c|c|c|c|}
\hline \multicolumn{5}{|c|}{ Roles en función del género y su orden en el relato. } \\
\hline & \multicolumn{2}{|c|}{ Personaje 1} & \multicolumn{2}{|c|}{ Personaje 2} \\
\hline & Mujeres & Hombres & Mujeres & Hombres \\
\hline Esposo/a & 14 & 21 & 20 & 12 \\
\hline Padre/madre & 20 & 5 & 16 & 7 \\
\hline Ama de casa & 5 & - & 4 & - \\
\hline Trabajador/a & 30 & 14 & 16 & 12 \\
\hline Periodista & 13 & 16 & 5 & 1 \\
\hline Teleoperadora & 10 & - & 11 & - \\
\hline Celebridad & 6 & 5 & 3 & 2 \\
\hline Narrador/a & 13 & 18 & 5 & 6 \\
\hline Novio/a & 11 & 10 & 15 & 5 \\
\hline $\mathrm{Hijo} / \mathrm{a}$ & 3 & 13 & 3 & 10 \\
\hline Vecino/a & 5 & 1 & 6 & 1 \\
\hline Compañero/a & 12 & 12 & 16 & 6 \\
\hline Usuario/a & - & 6 & - & 5 \\
\hline No relevante & 9 & 10 & 6 & 11 \\
\hline Papel & 16 & 3 & 7 & 7 \\
\hline Otro & 28 & 41 & 29 & 35 \\
\hline
\end{tabular}

Fuente: Elaboración propia.

En aquellos roles clasificados como "iguales", dado su equilibrio de personajes masculinos y femeninos, la variable "orden en el relato” ofreció otra perspectiva de los resultados previos. Por ejemplo, en el papel de esposo/a el estudio de los protagonistas en función del género y orden en el relato subrayó la existencia de un mayor número de personajes masculinos que inician la interacción publicitaria (21 frente a 14 mujeres), frente a la mayoría de femeninos que la finalizan (20 frente a 12 varones). Una tendencia que se repitió, en menor media, en el caso del rol de periodista.

Esta mayor presencia de protagonistas masculinos en el Personaje 1 se produce, inclusive, en alguno de los papeles con mayoría femenina. Por ejemplo, el descriptor compañero/a presenta un equilibrio de protagonistas femeninos y masculinos que inician la interacción. No obstante, mientras la presencia masculina en el Personaje 1 supone la mayoría para ese papel, la presencia femenina es superior en el Personaje 2. 
La desigual distribución de los personajes masculinos y femeninos en un determinado rol, atendiendo a quién toma la iniciativa en la interacción publicitaria, puede vincularse a la existencia de una serie de estereotipos de género. Estereotipos que subrayan la existencia de diferencias lingüísticas y sociolingüísticas entre mujeres y hombres. "La imagen estereotipada del habla masculina funciona siguiendo las reglas de conversación, mientras que la del habla femenina tiende a hacer mayor caso de las propiedades de la implicación conversacional” (Lakoff, 1981: 137).

\section{Principales roles femeninos y su relación con los personajes masculinos}

El análisis de los roles desempeñados por los personajes femeninos y masculinos en la publicidad sonora posibilitó profundizar en el tipo de relación desarrollada en la interacción publicitaria. Una relación que, junto con la distribución de los diferentes papeles en función del género, permitió determinar la existencia de sexismo en las representaciones femeninas de la muestra.

Los principales roles que asumen los personajes femeninos en la publicidad radiofónica analizada, atendiendo al número de sujetos que los desempeñan, se corresponden con los de trabajadora (rol laboral) ${ }^{4}$, madre, esposa, compañera y novia.

Figura 4. Principales roles femeninos.
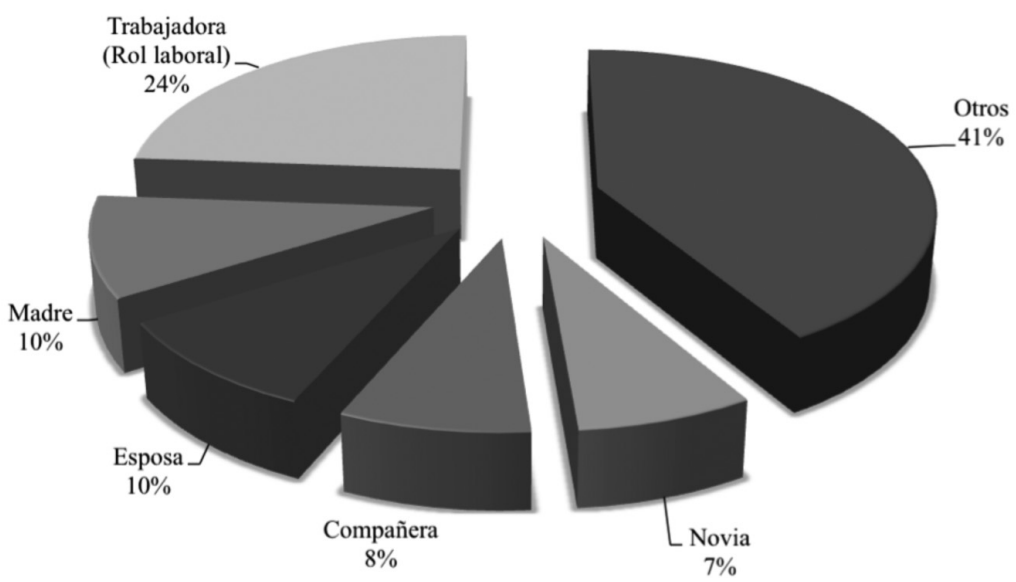

Fuente: Elaboración propia.

4 Para hacer referencia a aquellos roles femeninos más habituales en la publicidad radiofónica se ha optado por reunificar, bajo la denominación de trabajadora, aquellos clasificadores vinculados al ámbito laboral (trabajadora, teleoperadora y periodista). La adopción del término genérico para referirse a la categoría resultante de esta reunificación puede llevar a confusión con el clasificador de trabajadora, por lo que se ha diferenciado su uso con la especificación de "Rol laboral". 


\subsection{Trabajadora (Rol laboral)}

El papel de trabajadora se configura como el más frecuente de la muestra de estudio al ser desarrollado por 46 de las 357 protagonistas, lo que supone el $13 \%$ de los personajes femeninos principales. Una presencia que adquiere mayor relevancia si se tienen en cuenta aquellas protagonistas en los papeles de teleoperadora y periodista; dos roles determinados por el tipo de actividad laboral desempeñada y que, sumados al de trabajadora, constituyen una cuarta parte de los personajes femeninos analizados (un total de 85 sujetos).

Este importante porcentaje de protagonistas que asumen papeles vinculados al ejercicio profesional podría llevar a pensar que la publicidad radiofónica presenta una imagen femenina más próxima a la de la mujer contemporánea que el clásico "ángel del hogar", arquetipo de la perfecta madre, ama de casa y esposa. No obstante, un análisis de los personajes femeninos en este rol reveló que dichas protagonistas desempeñan su actividad en puestos "tradicionalmente femeninos", que constituyen una prolongación de sus tareas domésticas como la limpieza (asistenta) o la auxiliaridad (enfermera, dependienta, azafata, teleoperadora).

Ejemplos 1, 2 y 3. Rol de mujer trabajadora.

Voz over (V.O.) Blanca Escobar, servicio de limpieza.

- En Barcelona Glorias no hacen más que fastidiarme. Por si fuera poco tener que limpiar espacios interminables, ahora encima van a traerme más gente. No se les ha ocurrido otra cosa que amenizar las noches de verano con música en directo en las terrazas, y yo limpia que te limpia, y bueno... por lo menos trabajaré bailando. La la la la...

V.O. Ven a la Plaza de las Constelaciones de centro comercial Barcelona Glorias cada día, de lunes a viernes, a las 9 de la noche. Te invitamos a un concierto al aire libre.

- Información, ¿dígame?

- ¿Me da el teléfono de los bomberos?

- ¿De donde es usted?

- Yo soy Móstoles

- ¿Que dónde reside?

- En Arganda

- Pues tome nota del teléfono de los bomberos de Arganda

- ¡Hombre!, es que hasta que lleguen hasta aquí.. 
- Pero vamos a ver, $i$ de donde llama?

- Desde mi empresa en Aljete

V.O. Vivas donde vivas, trabajes donde trabajes, marca el 112. Una nueva forma de llamar a todas las emergencias en la comunidad de Madrid. Todos en 112.

- (SFX. megafonía) En “Supermercado” contamos con un amplio surtido de jamones para regalar.

- (SFX. megafonía) En la sección de "Imagen y sonido" encontrará Canal+ un regalo que no va directo a la pistolera.

- (SFX. megafonía) i¿No me estarás llamando obesa?!

- (SFX. megafonía) No, sólo digo es en lo único en que piensas es en comer mientras yo pienso en Deep Impact, Mercury Rising.

- Esta Navidad ningún regalo se puede comparar a Canal+. Llama a 902201515.

Dentro de este rol laboral, las protagonistas femeninas establecen fundamentalmente relaciones de complementariedad con sus interlocutores. Una situación lógica si se atiende al hecho de que la principal caracterización de este papel se realiza por medio de sus acciones, por las que se entabla la relación de auxiliaridad con el demandante de la ayuda; ya sea cliente, enfermo, pasajero de un avión, etc.

\subsection{Madre}

El rol de madre supone uno de los papeles femeninos más habituales de la publicidad tradicional y, como se pudo extraer de este análisis, de la radiofónica. Un papel que fue desempeñado por un total de 36 personajes femeninos, que configuran un $10 \%$ de las protagonistas de la muestra.

En lo que se refiere a los personajes que interactúan con la madre dentro del relato publicitario, y pese a que en la selección objeto de estudio existen diversos personajes masculinos que desempeñan el papel de padre, la verdadera relación de complementariedad de este rol se establece con el hijo. Un rol que es asumido, en su mayoría, por personajes masculinos.

De este modo, entre ambos papeles se establecen dos tipos de relación: la de complementariedad madre-hijo, y la relación de contrapunto que pretende la armonía sonora de voces masculina-femenina.

En la caracterización de ambos roles, madre e hijo, son habituales las alusiones de otro personaje (en este caso el complementario), a modo de vocativo (mamá, hijo, etc.). 
Ejemplos 4 y 5 . Rol de madre.

- Mamá, me han regañado en la oficina.

- A mi niño y ipor qué?

- Nada, confundí a nuestro mejor cliente con un mensajero.

- Lo que pasa es que te tienen manía.

- Y metí un sobre lleno de cheques en la trituradora.

- Ummm. ¡Te tienen envidia porque eres el más listo del mundo!

- V.O. ¿Acaso no se merece tu madre un regalo? En PRYCA hemos seleccionado los mejores artículos para que quedes como un rey el próximo día de la madre. En PRYCA.

- ¡Hala, la música a todo trapo! ¡Si es que vas a acabar trastornado! Toma hijo, tu bocata de chorizo de Pamplona, y ten cuidado con las migas.

(SFX. Ovación de gente)

- Oye, y haz el favor de terminarlo, que no me comes nada!

- ¡Mamá, no quiero comer ahora! ¡Y baja del escenario!

- V. O. Si pase lo que pase sabes que lo tuyo es la música, sigue tocando. Pepsi te sigue. Pepsi. Generation Next.

Resulta interesante destacar la existencia de un cierto conservadurismo a la hora de enfocar estos personajes; la madre es uno de los personajes más recurrentes de la publicidad general de todos los tiempos y el hijo su complemento-contrapunto más socorrido.

\subsection{Esposa}

Por su parte, el rol de esposa, otra de las representaciones clásicas de las mujeres en la publicidad tradicional, aparece desarrollado en la publicidad radiofónica de forma equilibrada por personajes femeninos y masculinos. En efecto, estos protagonistas femeninos suelen interactuar con sus correspondientes masculinos dentro del relato, manteniendo una relación de complementariedad.

Ejemplos 6 y 7. Rol de esposa. 
- ¡Paco! ¡Paco no te muevas! Que hay un bicho enorme ahí junto al ordenador. ¡Ñ̃̃̃ñn!

- Pero Carmen ¿qué haces? Que era Mariano, el vecino, que estaba bajando una cosa de Internet. Como el pobre no tiene ONO... ¡Mariano! ¡Mariano! Ah, mira se le movió una antenita.

V.O.1. Si aun no tienes Internet de banda ancha ONO, eres un bicho raro. Internet de alta velocidad con tarifa plana por menos de un euro al día. Llama al 1.400 y apúntate.

V.O.2. Si aun no tienes Internet de banda ancha ONO, eres un bicho raro. Internet de alta velocidad con tarifa plana por menos de un euro al día. Llama al 1.400 y apúntate.

- Mari Cruz Morales radiante en la fiesta del Casino de Mónaco. ¡Ay! ¡Si me vieran las amigas! Mari Cruz Morales nos abre las puertas de su mansión en Marbella, con 16 cuartos de baño. ¿¿A ver? ¡Ay! ¡Ésta está bien!

- ¡Mari Cruz, déjate ya de revistas y apaga la luz!:Que son las 4 de la mañana!

- V.O. Aprende a ser millonario. Este viernes Supercuponazo de la ONCE. Por 200 pesetas 200 millones.

- ¡Ahora te vas a enterar! Mari Cruz Morales se divorcia, ¡chúpate esa!

\subsection{Compañera}

El rol de compañera, que presenta una mayoría de protagonistas mujeres en la muestra de estudio, se refiere a aquellos personajes que interactúan con un igual en el ámbito personal, laboral, académico, etc. Este papel identifica a los personajes que entablan una relación de igualdad o de contrapunto, en el caso de las interacciones mixtas de un personaje masculino y otro femenino, con los protagonistas que asumen el mismo rol.

En ocasiones incluso se llega a omitir uno de los personajes del relato, circunstancia que favorece la sensación de que la protagonista está estableciendo una relación de amistad con la audiencia. Esta sensación queda potenciada por la intimidad del medio radiofónico.

Ejemplos 8 y 9. Rol de compañera.

- Pedro me hace sentir tan bien, con él estoy tan a gusto, es tan seguro, lo tiene tan claro... pero Mario... Mario es pasión, es emoción, todo él es una aventura... mmmm

V.O. En la vida no puedes tenerlo todo, pero en informática sí. Ven a Informat del 18 al 24 de noviembre, en Fira de Barcelona. 
- El otro día, el pequeño, el que tiene diez meses, dijo su primera palabra. Llamó mamá a la canguro.

V.O. Si tu trabajo te roba todo tu tiempo necesitas incorporara la informática a tu vida. Ven urgentemente a Informat, en Feria de Barcelona, del 19 al 24 de abril.

El papel de compañera presenta características similares al de vecina, rol del que se ha diferenciado en ocasiones gracias a la presencia de un paisaje sonoro que permitió su localización en un espacio doméstico (vecinas) o fuera de éste (compañeras). No obstante, frente al camaraderismo presente en el rol de vecina, tradicionalmente femenino, la representación publicitaria del papel de compañero/a está habitualmente vinculada a agrupaciones de composición masculina o mixta (Martín-Llaguno, Quiles y López Sánchez, 2004: 369).

\subsection{Novia}

Finalmente, el papel de novia constituye otro de los roles más habituales de los personajes femeninos con predominio sobre los masculinos (26 y 15 personajes respectivamente).

Aunque entre los protagonistas que desarrollan este papel se establecen relaciones de complementariedad y, por tanto, debería existir una igualdad entre personajes masculinos y femeninos, la realidad es que la novia de la muestra interactúa con otros individuos en el relato publicitario.

Ejemplos 10 y 11. Rol de novia.

- ¡Te quiero!

- ¡No puede ser!

- ¡Que sí que te quiero, mujer!

- ¡Ay!, ¿ de verdad?

- Sí, te quiero.

- ¡Dímelo otra vez!

- Definitivamente te quiero.

- ¡Repítelo dos veces más!

- ¡Te quiero!;Te quiero!

- No

- Que sí 
V.O. Hay cosas que para decirlas necesitan su tiempo, pero por mucho que hablen, una llamada metropolitana de una hora, en el horario más caro, solo cuesta 139 pesetas. Pocas cosas cuestan tan poco. Telefónica.

- Y tú María, ¿quieres a José Luis como esposo, para amarle y respetarle en la salud y en la enfermedad, en la riqueza y en la pobreza, hasta que la muerte os separe?

- Eh, no sé, eh... No sé... es que eso es mucho tiempo ¿sabe usted? Mi madre siempre dice que la vida da muchas vueltas.

V.O. Si buscas algo en lo que realmente poder confiar, con la máxima calidad y fiabilidad, Ford Focus, porque tú buscas algo más.

Entre los personajes vinculados al de novia dentro de la interacción publicitaria adquiere especial interés el de sacerdote; rol que asume un papel complementario dentro del mensaje sonoro.

El análisis de las representaciones femeninas existentes en los anuncios radiofónicos de la muestra subrayó un claro predominio de aquellos papeles que tradicionalmente le asignó la publicidad, como el de madre, esposa o novia, y de determinados trabajos como el de teleoperadora (versión sonora de la clásica secretaria).

Estos resultados ratifican las conclusiones de los estudios precedentes en torno a las representaciones de género en la publicidad sonora. En efecto, desde el estudio pionero de Furham y Schofield (1986), todas las investigaciones llevadas a cabo en este ámbito destacan un predominio de representaciones femeninas en roles “dependientes”. Esta circunstancia confirma la existencia de diferencias relevantes en la representación de los personajes femeninos y masculinos dentro de la publicidad radiofónica.

\section{Conclusiones}

El estudio llevado a cabo en torno a los roles femeninos y, por extensión, a los masculinos en la publicidad radiofónica presentada al Festival Publicitario de San Sebastián ha permitido extraer las siguientes conclusiones:

Desde la primera aproximación a la publicidad objeto de estudio se hace patente la existencia de una infrarrepresentación de las voces femeninas. Solamente el $41 \%$ de las piezas radiofónicas inscritas a la categoría de radio del festival cuentan con -al menos- una voz de mujer.

El análisis de las representaciones de género que vehicula la publicidad radiofónica ha puesto de relevancia la existencia de diferencias entre los papeles asumidos por los protagonistas femeninos y masculinos. Papeles que han sido definidos, en su mayoría, a través de las propias acciones del personaje (68\%). 
Estas diferencias, que han permitido señalar la existencia de roles exclusivos de uno u otro género (como ama de casa, teleoperadora o usuario), se hacen especialmente patentes de tener en cuenta que el análisis se ha limitado a aquellos personajes masculinos que acompañan a las voces femeninas en el anuncio y, por tanto, condicionados por las relaciones establecidas en la interacción publicitaria (relaciones de complementariedad o contrapunto).

Asimismo, se ha constado la existencia de estereotipos de género de carácter lingüístico y sociolingüístico que han influido en el mayor porcentaje de personajes masculinos que inician la interacción verbal (60\% de voces masculinas frente al 53\% de voces femeninas como Personaje 1), o en su superioridad en determinados papeles como el de narrador.

En el ámbito concreto de las representaciones femeninas los roles más frecuentes desempeñados por las protagonistas de la publicidad radiofónica son los de trabajadora (28\%), madre (12\%), esposa (11\%), compañera (10\%) y novia (9\%). Unos papeles que responden, en su mayoría, a una perspectiva muy tradicional de las mujeres en la publicidad. De igual modo sucede con aquellos personajes femeninos que desempeñan un rol laboral. Su mayor presencia, lejos de reflejar una evolución positiva de dichas imágenes, está asociada a características clásicas de la feminidad como auxiliaridad (teleoperadora, dependienta, señora de la limpieza) o belleza (azafata, modelo).

La concepción tradicional de los roles desempeñados por los personajes femeninos fue ratificada por el tipo de relación que estas protagonistas desarrollan con sus interlocutores varones dentro del anuncio publicitario; en su mayoría relaciones de complementariedad (esposo-esposa, madre-hijo, compañero-compañera, etc.).

Esta circunstancia se corresponde con una tendencia, destacada en la investigación en torno a las representaciones de género en la publicidad radiofónica desde Furham y Schofield (1986), de representar a los personajes femeninos en roles dependientes. Unos papeles que adquieren particular relevancia en el medio sonoro dado que, para generar una imagen unívoca en la mente de sus oyentes, la publicidad radiofónica acude a aquellas representaciones más conocidas, en muchos casos a coste de su actualización.

Finalmente, si se atiende a la definición aportada por Michel (1987: 17), se puede concluir que existe sexismo a la hora de representar a los personajes femeninos y masculinos en la publicidad radiofónica. En efecto, sus mensajes subrrepresentan e, incluso, excluyen a los personajes de determinados roles atendiendo a su pertenencia a uno u otro género. Asimismo, la publicidad sonora estereotipa a los personajes femeninos y masculinos en función de unas creencias y valores socialmente admitidos, tanto desde la perspectiva de parámetros fónicos y costumbres conversacionales, como de una serie de características implícitas en la construcción social de la feminidad (físicas y psicológicas).

En definitiva, los mensajes publicitarios que vehiculan el medio radiofónico presentan un abanico limitado de representaciones femeninas que refleja una imagen convencional y sexista de los roles desempeñados por las mujeres. 


\section{Referencias bibliográficas}

Areste (2003): Arrinconando estereotipos de género en medios de comunicación y la publicidad. Madrid: Dirección General de la Mujer.

Berganza, M. R.; Del Hoyo, M. (2006): “La mujer y el hombre en la publicidad televisiva: imágenes y estereotipos”, Zer, n. 21, pp. 161-175.

Bigné, J. E.; Cruz, S. (2000): “Actitudes hacia los roles de género en la publicidad. Efectos sobre la imagen de empresa y la intención de compra”, Cuadernos de Economía y Dirección de la Empresa, n. 6, pp. 165-186.

Camps, V. (1998): El siglo de las mujeres. Madrid: Cátedra.

Courtney, A.; Lockeretz, S. (1971): "A woman’s place: an analysis of the roles portrayed by women in magazine advertisements", Journal of Marketing Research, n. 8, pp. 92-95.

Courtney, A.; Whipple, T. (1974): “Women in TV Commercials”, Journal of Communication, n. 24, pp. 110-118.

De Pablos, J. M. (dir.) (2005): Los nuevos modelos de mujer y de hombre de la publicidad televisiva actual, Equipo Latina de Comunicación Social. Disponible en: http://www.eccc.ucr.ac.cr/pdfs/consejocataluna.pdf. [Consultado el 15/01/2009].

Durkin, K. (1985): “Television and sex-role acquisition. I Content”, British Journal of Social Psychology, vol. 24, n. 3, pp. 101113.

- (1985): “Television and sex-role acquisition. II Effects”, British Journal of Social Psychology, vol. 24, n. 3, pp. 191-210.

- (1985): “Television and sex-role acquisition. III Counter-stereotyping”, British Journal of Social Psychology, vol. 24, n. 3, pp. 211-222.

Elósegui, M. (1998): Los roles de la mujer y el varón en la sociedad española y su reflejo en los anuncios de televisión. Zaragoza: Universidad de Zaragoza e Instituto Aragonés de la Mujer.

Fajula, A., Fernández Souto, A. B.; Barbeito, M. L. (2010): “Publicidad y género. Los estereotipos de la mujer en la publicidad radiofónica del 'prime time' generalista", en Actes de Congènere: la representació de gènere a la publicitat del segle XXI. Girona: Universitat de Girona, pp. 1-19.

Friedan, B. (1974): La mística de la feminidad. Madrid: Júcar.

Furham, A.; Schofield, S. (1986): “Sex role stereotyping in British radio advertisements”, British Journal of Social Psychology, n. 25, pp. 165-171.

Furham, A.; Thomson, L. (1999): “Gender role stereotyping in advertisements on two British radio stations”, Sex Roles, vol. 40, n. 1-2, pp.153-165. 
Galán, M. M.; Sánchez, M. I. (2005): “La Publicidad en el siglo XXI: Una Referencia a la Ética Empresarial”, en Fidalgo, A. (ed.): Livro de Actas. $4^{\circ}$ Sopcom. Repensar os Media: Novos Contextos da Comunicação e da Informação. Aveiro: Universidade de Aveiro, pp.789-798.

García Calderón, C. (2005): "Representaciones de la mujer en la publicidad Mexicana", Revista Científica de Información y Comunicación, n. 2, pp. 43-54.

Gil, E.M. (2007): “Los estereotipos de la mujer en la publicidad radiofónica”, en Durán, M. A.; Viedma, M. (coords.): Mujeres, simbolismo y vida. Málaga: Universidad de Málaga, pp.79-96.

Gilly, M.C. (1988): "Sex roles in advertising: a comparison of television advertisements in Australia, Mexico, and the United States”, Journal of Marketing, n. 52, pp. 75-85.

Goffman, E. (1979): Gender advertisements. Londres: Macmillan.

Hurtz, W.; Durkin, K. (1997): “Gender role stereotyping in Australian radio commercials”, Sex Roles, vol. 36, n. 1-2, pp.103114.

Instituto de la Mujer (2008): Observatorio de la Imagen de las Mujeres. Informes anuales. Madrid: Autor.

Lakoff, R. (1981): El lenguaje y el lugar de la mujer. Barcelona: Hacer.

López Lita, R.; Bernad, E., (2007): “Publicidad, medios de comunicación y segregación ocupacional de la mujer: perpetuación y superación de los estereotipos de género y sus consecuencias en el mercado de mano de obra”, Revista del Ministerio de Trabajo y Asuntos Sociales, n. 67, pp. 213-226.

Martín-Llaguno, M.; Quiles, M.C.; López Sánchez, M. C., (2004): “Los sistemas de autorregulación como mecanismos de control de la publicidad de tabaco: evaluación mediante análisis empírico”, Gaceta Sanitaria, vol. 5, n. 18, pp. 366-373.

Mcarthur, L.; Resko, B. (1975): “The portrayal of men and women in American television commercials”, The Journal of Social Psychology, n. 97, pp. 209-220.

Michel, A. (1987): Fuera moldes. Hacia una superación del sexismo en los libros infantiles y escolares. Barcelona: La Sal.

Neto, F; Santos, A. (2004): "Gender role stereotyping in radio advertisements: a portuguesa and cross-national analysis", Journal of Radio Studies, vol. 11, n. 1, pp. 131-145.

Royo, M.; Aldás, J; Küster, I. y Vila, N. (2005): “Roles de género y sexismo en la publicidad de las revistas españolas: un análisis de las tres últimas décadas del siglo XX”, Comunicación y Sociedad, vol. XVIII, n. 1, pp. 113- 152.

Sánchez Aranda, J. J.; García Ortega, C.; Grandío, M. M. y Berganza, M. R. (2002): El espejo mágico. La nueva imagen de la mujer en la publicidad actual. Pamplona: Instituto Navarro de la Mujer. 